\title{
AReview \\ Fundamentals on seaweed potential as a promising share of nutraceuticals in alleviating the obese problem
}

\author{
Karpakavalli Meenakshisundaram, Muthumareeswari Sethurajan, Ranjithkumar Dhanaraj, \\ Sangilimuthu Alagar Yadhav and Mohan Sellapppan
}

\begin{abstract}
SUMMARY
Herbal and non-herbal extracts achieve an increased and continuous welcome as nutraceuticals in Global market demand eg., Green tea for weight loss and cancer, Ginkgo biloba to improve cognitive activities and Glucosamine in arthritis. WHO reports as $80 \%$ of world's population relies on traditional medicine, historically provided many novel drug leads and plays a pivotal role in the facet of drug discovery. Nowadays, seaweeds cultivation is becoming very essential, as there is an inadequate natural seaweeds stock to meet the industrial need. For more than thousands of years, the medicinal effects viz., treatment of burns, rashes and wounds, of seaweeds are well established. From the literature, the marine sponges do contain many chemicals and are the good sources of minerals, vitamins, proteins, carbohydrates, and fibers. However, the potential effects of these nature-based species, are awaiting exploration. These challenges can be overcome by the advent of new nutraceutical formulation, which do ensure a bio-enhancing, immune-stimulating and a drug adjunct effect in bioactivities. Edible seaweeds offer interesting possibilities to develop healthier drugs and are the formidable source of nutrients and bio-compounds with proven benefits against degenerative metabolic diseases and Obesity.
\end{abstract}

Key Words : Fundamentals, Seaweed potential, Promising share, Nutraceuticals, Alleviating, Problem

\section{MEMBERS OF THE RESEARCH FORUM}

Author to be contacted :

Karpakavalli Meenakshisundaram, Department of Pharmaceutical Chemistry, Karpagam College of Pharmacy, Coimbatore (T.N.) India Email : mskresearch81@gmail.com

Address of the Co-authors:

Muthumareeswari Sethurajan, Department of Nutrition, Thassim Beevi Abdul Kadar College for Women, Kilakarai, Ramanathapuram (T.N.) India

Ranjithkumar Dhanaraj, Department of Pharmaceutical Analysis, Prime College of Pharmacy, Erattayal, Palakkad (Kerala) India

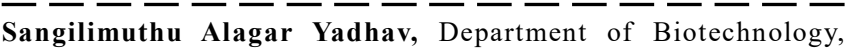
Karpagam University, Coimbatore (T.N.) India

Mohan Sellapppan, Department of Pharmaceutics, Karpagam College of Pharmacy, Coimbatore (T.N.) India
How to cite this article : Meenakshisundaram, Karpakavalli, Sethurajan, Muthumareeswari, Dhanaraj, Ranjithkumar, Yadhav, Sangilimuthu Alagar and Sellapppan, Mohan (2021). Fundamentals on seaweed potential as a promising share of nutraceuticals in alleviating the obese problem .Internat. J. Plant Sci., 16 (AAEBSSD): 86-94, DOI:10.15740/HAS/IJPS/16.AAEBSSD/86-94, Copyright @2021: Hind Agri-Horticultural Society.

Article chronicle : Received : 10.07.2021; Accepted : 25.07.2021

$O_{1}$ eaweeds: Globalization has led to healthy living consciousness. Houghton (1995) suggests -in the modern medicines consist of active principles from traditional medicines Eg. Digitalis and papavir species. 
Karpakavalli Meenakshisundaram, Muthumareeswari Sethurajan, Ranjithkumar Dhanaraj, Sangilimuthu Alagar Yadhav and Mohan Sellapppan

Untapped potentials are present abundantly in marine resources which are the richest source of plants and animals. Eating trends of natural food sources have been augmented to bring health and vitality and one such natural resource is seaweeds, wonder plants of the sea. Facilitated and a luxuriant growth of seaweed is observed in southern coast of India.

Seaweeds are called as medical food of the $21^{\text {st }}$ century. Seaweeds are the new renewable and valuable source of food, energy, medicines and pharmaceuticals. Seaweeds, as offer untapped plethora of health benefits, play a milestone in pharmaceutical industries, food, confectionary, dairy, textile, paper, paint and varnish industries as gelling, stabilizing and thickening agents and in modern biology since from 1995.

Seaweeds found along the Indian coastline have immense nutritional potential; are good, new renewable and valuable source of anti-oxidants, antibiotic substances (Chennubhotla et al., 1991) and rich nutrient contents with more than 60 trace elements, a much higher concentration than in terrestrial foodstuffs/land plants and thus found to be useful in treating major degenerative and deficiency diseases.

Based on the size, phytoplankton (microalgae, with 5000 different species) and seaweed (macroalgae with 6000 species) are the two major groups of Algae. Theses seaweeds are further grouped as green, brown, red and blue-green algae, depending upon the variation of pigment or morphological and /or anatomical structures. In total, there are at least 291 species used worldwide from 43 countries. 33 chlorophytes, 75 phaeophytes and 163 rhodophytes. About 145 species used for food and 110 species for phycocolloids (polysaccharides like alginates, agar and carrageenan from seaweeds) productions. So far, around 271 genera and 1153 species of such seaweeds have been reported from the Indian waters.

Seaweeds like Ulva sp., Enteromorpha sp., Caulerpa sp., Codium sp., Monostroma sp., Sargassum sp., Hydroclathrus sp., Laminaria sp., Undaria sp., Macrocystis sp., Porphyra sp., Gracilaria sp., Eucheuma sp., Laurencia sp. and Acanthophora sp. has high protein content, carbohydrates content and fiber contents; minerals and vitamins esp., iodine; are popularly being used by many of the countries like Japan, China, Korea, Malaysia, Thailand, Indonesia, Philippines and other South East Asia.

\section{Resources of seaweeds:}

0.6 million tons of seaweeds are available in India. Production of seaweeds is dominated by Indonesia, China, and the Philippines. Indonesia produces 5.7 million t of Euchema (27\% of total world seaweed production in 2012). China produces large amounts of Laminaria (4.8 million t; $23 \%$ of total), Gracilaria (1.9 million t; $9 \%$ of total); Undaria (1.7 million t, $8 \%$ of total) and Porphyra (1.1 million t; $5 \%$ of total). In Philippines, Euchema dominates with 1.7 million t produced, $8 \%$ of the global seaweed production.

Seaweeds are found attached to the solid bottom substrate of rocks, dead corals, pebbles, shells and other plant materials; also, in relatively shallow coastal waters, estuaries, intertidal and deep-sea areas up to 180 meters depth. Different varieties of seaweeds can be seen as available in plenty along the long coastal belt of India and found to be stretched in the intertidal or sub-tidal regions of the sea.

Seaweeds Grow abundantly and the potential areas in India for rich beds of several species of green, brown and red algae are on the southeast coast of Tamil Nadu say Kanyakumari, Lakshadweep, Gulf of Mannar, Andaman-Nicobar Islands and Gujarat coast. Also rich seaweeds beds on west coast areas of Mumbai, Ratnagiri, Goa, Karwar, Varkala, Vizhinjan and Pulicat in TN and Chilka lakes in Orissa.

Review on seaweed resources along the Indian coast reported that total standing crop varied from 6,77 , 308.87 to $6,82,758.87$ tons (fresh weight). The seaweeds spreads along the Indian coastline and its nine maritime states and islands (Gujarat-1700, Maharashtra-572, Goa104, Karnataka-280, Kerala560, Tamil Nadu-980, Andhra Pradesh-960, Orissa-432, West Bengal-280, Andaman and Nicobar Islands-1500 (approx.), Lakshadweep Islands-120 (approx.) in km.

\section{Domestic seaweed cultivation:}

Nowadays, seaweeds cultivation is becoming very essential, as there is an inadequate natural seaweeds stock to meet the industrial need. Worldwide survey says that Asia stands first in seaweeds cultivation and in that, China, Japan, Korea, Indonesia and Philippines are, already, in pipeline of this production. Though India is bestowed with a coastline of more than $17,000 \mathrm{~km}$, embracing 821 species of seaweeds, its cultivation is only recently started practiced in certain coastal districts of Tamil Nadu and Gujarat states. 
Fundamentals on seaweed potential as a promising share of nutraceuticals in alleviating the obese problem

Seaweed cultivation should be encouraged and undertaken all over the Indian coasts including Chilka Lake, Palk Bay, Andaman Islands and Lakshadweep Islands as seaweed cultivation is ecologically safe and does not damage the marine ecosystems. Cultivation and utilization of seaweed as an important and profitable livelihood option for the coastal fishing community. Seaweeds form an important renewable resource in the marine environment and have been a part of human civilization from time immemorial. The importance of seaweed could play a catalytic role in rejuvenating the rural economy.

Seaweeds farming is eco-friendly; a major tool to treat coastal pollution in the sea and reduce $\mathrm{CO}$ in global warming. Culture of high-value seaweeds with superior growth and rich nutritional characteristics to be aimed for. Seaweed farming has the potential to generate further socio-economic benefits to coastal communities in tropical regions, given the rising global demand for seaweed derived products; has emerged as the most relevant livelihood strategy. The most relevant livelihood strategy. Given the rising global demand for seaweed derived products, seaweed farming has the potential to generate further socio-economic benefits to coastal communities in tropical regions.

\section{Benefits of red variety seaweeds:}

Three divisions of seaweeds viz., Chlorophyta (green algae, 900 species, eg., Ulva lactuca, Enteromorphain tenstinalis), Phaeophyta (brown algae, 1500 species eg., Padina gymnospora, Saragassum linifolium) and the Rhodophyta (red alage, 4000 species, eg., Gracillaria verrucosa, Hypnea musciformis) found in nature (Elder, 2004).

Greatest variety of red algae found in subtropical and tropical waters, brown more common in cooler, temperate waters. With accordance to high protein and amino acid composition, red seaweeds appear to be potential source of food protein. Comparing to brown algae (upto $15 \%$ ), green and red varieties are found to be rich in protein content (up to $30 \%$ ); red and brown seaweeds are considered as a rich source of bioactive secondary metabolites; and also red algae is devoid of any side effects, whereas a few side effects being observed in green sponges, this because, later can accumulate heavy metals from the surrounding contaminated water and could be toxic to the body. Bioactive secondary metabolites such as steroids, flavonoids, glycosides, alkaloids and insecticides related active metabolites are seen to be rich in red and brown seaweeds and are of great medicinal value. Agar yielding red seaweeds are collected throughout the year; alginates yielding brown varieties are collected from August to Janauary month on southern coast. Intertidal sub tidal regions. By all the above, red algae species are preferred over to other two varieties for our project.

\section{Chemical constituents of seaweeds:}

From the literature, the marine sponges do contain many chemicals and are the good sources of minerals, vitamins, proteins, carbohydrates and fibres. Phycocolloids viz., Agar, Alginates (absorb water, become gel), Alginic acid, Carrageenan (laxative), Mannitol, Fucoidin, laminarin and iodine have wide uses. Alginates, fucoidans, and laminarin are present in brown algae; carrageenan and agaran are characteristic of red algae; while green algae are characterized by their content in ulvan. Various active compounds include sulphated polysaccharides, phlorotannin, carotenoids (e.g. fucoxanthin), minerals, peptides and sulfo-lipid, with proven benefits against degenerative metabolic diseases.

Owing to the balanced content of micronutrients, seaweed stands against diseases and infections, also, builds resistance in the same regard. The minerals like calcium, chlorine, chromium, cobalt, lithium, magnesium, potassium, phosphorus, silicon, sodium, sulfur and micronutrients like boron, zinc, iodine, iron, copper, selenium, fluoride, molybdenum, manganese, nickel, cobalt which is required for the efficient functioning of vital organs and for alleviating the ill effects of blood pressure and blood sugar alteration.

Algae contain various of the essential amino acids such as glycine, alanine, proline, arginine, glutamic, and aspartic acids and phycobiliproteins. Phytonutrients type metabolites are mainly represented by phenolic acids, tannins, flavonoids, terpenes, catechins, and phlorotannins, as well as pigments like chlorophyll, carotenoid (fucoxanthin) and phycobiliproteins.

Vitamin E estimate differs $8.8-12.0 \mathrm{mg} / \mathrm{kg}$ in green algae, $10-26 \mathrm{mg} / \mathrm{kg}$ in red, and 1.6 to $122 \mathrm{mg} / \mathrm{kg}$ in brown algae. Regarding vitamin B12, its content ranges from 4.9 to $1000 \mathrm{mg} / 100 \mathrm{~g} \mathrm{~d}$.w. for green algae, 612 to 900 $\mathrm{mg} / 100 \mathrm{~g}$ d.w. for brown algae and 95.1 to $1000 \mathrm{mg} / 100$ $\mathrm{g}$ d.w. for red algae.

\section{Biological properties of seaweeds:}

The Chinese and Japanese have used seaweeds to treat goiter and other glandular problems since $300 \mathrm{~B}$. 
Karpakavalli Meenakshisundaram, Muthumareeswari Sethurajan, Ranjithkumar Dhanaraj, Sangilimuthu Alagar Yadhav and Mohan Sellapppan

C. The rhodophycean algae Digenia simplex is made into a drug in China as an antihelmenthic. The Roman used seaweeds to heal wounds, burns and rashes. The English used prophya to prevent scurvy and chondrus, gracilaria and pteroclodra for treatment of various internal disorders such as constipation, stomach aches, and ulcers. Extracts of Vocca and Walsh were effective against both gram positive and gram-negative bacteria.

Previously, seaweeds were only used as gelling and thickening agents in the food or pharmaceutical industries, recent researches have revealed their potential as complementary medicine. for health and disease management, such as tissue healing properties. immune stimulatory and /or modulatory effects, antiviral, antifungal, anti-bacterial, anti-oxidant, anti-inflammatory, anti-coagulant, anti-thrombotic, anti-diabetic, antihypertensive, anti-hyperlipidemic, anti-obesity, antiestrogenic, thyroid stimulating, neuro-protective, antidepression effects, anti-tumour/anti-proliferation/anticancer/anti-metastatic, in the treatment of tuberculosis, arthritis, rheumatism, other aches and pains, colds, influenza, bone health and mental health benefits and therapeutic effects in surgery and brain injury (White et al., 2014).

Seaweeds and other marine natural products contain variety of sterol, which are used as hypotensive and also to treat arthritis, rheumatism and other aches and pains. They have curative powers for the treatment of tuberculosis, colds and influenza. Many companies producing a seaweed powder from Ascophyllum nodosum for beauty and body care products.

Some of the medical uses of algal species are as: Digenea spas an effective vermifuge; Undaria sp. to inhibit the Herpes simplex virus and to treat breast cancer; Ptilota $s p$ produces a protein (a lectin) that agglutinates human erythrocytes; Corallina sp. to be used in bone replacement therapy, Asparagopsis taxiformes and Sarconema $s p$ are used to cure goiter and seaweed extract, heparinoids, inhibiting throbin activity, used in cardiovascular surgery.

\section{Medicinally important phytoconstituents of seaweeds:}

Recent findings reveal that terpenoids eg., in the ethanolic extract of Salvia potentillifolia have potential cholinesterase inhibitory activity, neuroprotective effects against ischemic and glutamatergic neurotoxicity, 6hydroxydopamine toxicity, and oxidative stress. Phytol in the marine red alga Gelidiella acerosa, has bioprotective potentials viz., the antioxidant and anticholinesterase activity and against neurological disorder, AD; Phytol act as immunostimulants by providing long-term memory induction and activating both innate and acquired immunity (Chowdhury and Ghosh, 2012) and antinociceptive activity (Santos et al., 2013). Phytol, a diterpene has antimicrobial action against Staphylococcus aureus and tuberculosis (Inoue et al., 2005; Saikia et al., 2010). Chang et al., (2007). Polyphenols from seaweeds has beneficial effects for cancer chemoprevention (Abirami and Kowsalya, 2012), by acting either as an antioxidant (Ganesan et al., 2018) or as a pro-oxidant on food (Ganesan et al., 2019b).

\section{Significance of seaweeds:}

As English medicines do execute a negative treatment effect of any untoward reactions, the usage of plant/marine algae/spice derivatives, especially their phyto-chemical is becoming more popular in combating degenerative and deficiency diseases owing to their potency.

The future outcome of any nutraceutical project is to develop supplement formula with natural seaweed to eradicate the micro nutrient deficiency prevailing in major cities. This formula with seaweed will be used in all types of nutrient deficiencies to have potential health benefits to the common people. This could help in meeting the food and nutritional security of the country.

Due to the increasing interest of consumers for a potent, healthier and side effects free formulation, the pharmaceutical industry has to face the double challenge of producing healthier processed medicines with more organoleptic palatability, high technological attributes, and with no commercial viability of the final form. Edible seaweeds offer interesting possibilities to develop healthier drugs and are the formidable source of nutrients and bio-compound like polysaccharides, omega-3 fatty acids, protein, carotenoids, phenolic compounds, vitamins, and minerals.

Seaweeds offers the opportunity of improving the intake of other minerals that would not be present in other drug equivalents. Also, the seaweeds have a low $\mathrm{Na} / \mathrm{K}$ ratio which is a suitable feature to prevent hypertension and cardiovascular disease risks. Therefore, the incorporation of seaweeds to drugs or as plain ingredient in nutraceutical formulation can be an excellent opportunity for the pharma sector to design products with additional promising health benefits.

Though, there are many mineral sources, viz., 
Dates, Atthipalam, Murungai leaves etc. and also, though, they all do contain a very rich possession of this mineral in them, the point is that the absorption of minerals from them into the organism is not to the expected level i.e. the bioavailability of minerals especially iron and zinc from seaweeds is only comparatively very significant, this because of the ability of seaweeds to absorb inorganic substances from the environmental resources. The therapeutic index of medicines gets usually increased to a marked level if a suitable nutrient is in adjunct to it, as it is well stated in many medical scientific reports (Kupper et al., 1998; Teas et al., 2004; Villares et al., 2002).

As micronutrients were found to be high in selected seaweeds such as iron in the range of $14.8-72 \mathrm{mg} / 100$ $\mathrm{g}$, iodine $38.8-72.2 \mathrm{mg} / 100 \mathrm{~g}$, and calcium $410-870 \mathrm{mg} /$ $100 \mathrm{~g}$. The essential amino acids were between 189.2 and $306 \mathrm{mg} / \mathrm{g}$, essential fatty acid like arachidonic acid was $0.80 \%$ and $0.59 \%$ of linoleic acid, monounsaturated fatty acid was $3.05-14.08 \%$ in $U$. fasiciata. Heavy metals like mercury exits in $0.030 \mathrm{ppm}$ in $A$. spicifera, arsenic $0.012-0.076 \mathrm{ppm}$, cadmium lies in the range from 0.012 to $0.081 \mathrm{ppm}$ in all species. And thus, it is derived by RDA as a precise nutrient's combination, an advisable food substitute for pregnant women to meet food security defiance, as they meet more than $70 \%$ of macro and micronutrients in them.

Edible seaweeds are rich in protein content with all essential amino acids and used as a nutraceutical supplement nowadays. Raising demand of fetal development can be met with nutraceutical supplementation and thus seaweeds found to be a best alternative source of supplementation without any side effects.

Seaweeds, being recognized as a rich source of macro and micro-nutrients and bioactive components, play a major role in food, nutraceutical and pharmaceutical industries thereby to subside the risk factors of Obesity, type-2 diabetes and cardio-vascular diseases. However, a mechanistic evidence, to standardize and to assess the potential untoward reactions, if any, edible seaweeds, is mandatory and is a need to guarantee the health claims.

\section{Nutraceuticals, pharmaceuticals and food:}

According to AAFCO, 1996, 'Nutrient' means a feed constituent that supports a life while 'Nutraceutical' means any non-toxic food supplements, herbal products, probiotics and prebiotics, medical foods with proven health benefits and multiple therapeutic effect, no side effects, thus, grabbing the interest of more consumers.

Scientific evidences say that nutritional supplements with safety aspect and pharmaceuticals in efficacy point, when put together as Nutraceutical forms either as medicinal format (capsule, tablet/ powder) or as whole food (probiotic drink and yogurt) or included in foods (spices), able to prevent and treat the diseases.

According to the Seafood Source report, nonherbals, proteins and peptides are the fastest and lucrative growing segment; the global nutraceutical fueled by expansion in drug market segments, functional food and dietary supplements, has shown a tidal growth as rapidly growing industry (7-12\% per year) in recent past, in US, reported as food component business for 250 BNUS\$ and the drug market is 150 BNUS\$; Russia, Japan and China are the largest consumers; Nutraceutical market yearly growth rate has been observed in Middle East and Africa as $31 \%$, Hungary $20 \%$ and Russia $24.5 \%$. Indian companies supply the plant extracts and phytochemicals locally as well as globally, favorable pricing in pharma retail chain and increase in healthcare spending, all these become the causes for the flourishing nutraceutical market in India, will hike to almost $71 \%$ in next five years.

The therapeutic benefits of some of the nutraceutical ingredients are listed as follows: Probiotics, prebiotics for their Bone and Joint health; Vitamins and anti-oxidants (like phycocyanin and green tea) for their cancer risk reducing ability; minerals and garlic to improve heart well- being; fibers, garlic, ginseng and carbohydrates for immune system; natural lycopene to treat prostate and cervical cancers; Green tea in weight management lowering cholesterol; Gymnema, Momordica for Diabetic control; digestive enzymes; lipids and oils to enhance the maternal and infant health and valuable dairy base ingredients to support eye, skin, respiratory health aspects, weight management, cognitive, mental function and in cholesterol Reduction.

\section{Regulatory bodies for nutraceuticals:}

Following are the various acts incorporating set of rules to regulate production, distribution and to govern the nutraceutical market, which grant best opportunities to firms for manufacturing, selling and for nutraceutical product research and development; result based protocols; undertaking clinical trials; also regulations for licensing and registration of food business, packing and labeling, food product standard etc. 
Karpakavalli Meenakshisundaram, Muthumareeswari Sethurajan, Ranjithkumar Dhanaraj, Sangilimuthu Alagar Yadhav and Mohan Sellapppan

- Dietary Supplement Health and Education Act (DSHEA) passed in 1946.

- The Food Safety and Standard Rule, 2011 have been issued.

- Foreign Direct Investment Act passed in 2012 under Food Safety and Standard Authority.

\section{Nutraceutical products from selected seaweeds:}

Cadalmin Ace (Sargassum wightii Grivelle ext) $348 \mathrm{mg}$ : Its bioactive principle inhibits hydroxy methyl glutaryl coenzyme A reductase which is responsible for Obesity and Dislypidemia. It helps in decreasing fat from body and manages lipid profile i.e. increases HDL the good cholesterol and decreases LDL and VLDL the bad cholesterols. Vrikshamla (Garcinia Cambogia) $37.7 \mathrm{mg}$ : It has Anti -Inflammatory and anti -ulcerogenic properties. An Appetite suppressant, fights obesity and reduces production of Cholestrol and Triglycerides. It increases Satiety and converts carbohydrates to energy. Rosemary (Rosemarinus officinalis) 4mg: It is rich in carnosic acid an antioxidant which also exerts antiinflammatory anti-hyperglycemic effects, improves cholesterol levels prevents thickening of arteries walls, improves brain function, enhances blood circulation in the brain and supports weight loss.

\section{Challenges to be met in seaweed projects:}

However, the potential effects of these nature-based species, are awaiting exploration. Problems in Seaweeds industry includes overexploitation leading to a scarcity of raw material, poor quality raw material, labour shortages during harvesting, lack of technology in improving product processing quality and lack of information on new resources and no large-scale attempts for seaweed productions.

Until recently, there was a lack of phytochemical composition of edible sea weeds and still no reports about Marine Algae Products (MAPs) quality control, chromatographic profiles, chemico-physical properties, biological activities or molecular mechanisms. This current work adds to the reliability of this natural molecule as a good candidate for medical use in the future in Indian folk medicine and eatables. To analyze the in vitro studies and bio-availability of nutrients present in the selected seaweeds.

However, the potential effects of these nature-based species, are awaiting exploration. These challenges can be overcome by the advent of new nutraceutical formulation, which do ensure a bio-enhancing, immune- stimulating and a drug adjunct effect in bioactivities. Using this natural candidate, the development of novel and effective therapeutic seaweeds' phycocolloids or compounds can be identified against various degenerative and deficiency diseases.

\section{Scope of seaweeds in obesity:}

The potentials of dietary fibre say to promote satiety and weight loss; delay gastric emptying to improve glycemic control; enhance stool bulking to reduce gut transit time and increase defecation frequency; and enhance bile acid excretion, resulting in reduced lowdensity lipoprotein cholesterol (LDL-C) in blood, are owing to their viscous and water-binding properties within the gastrointestinal tract.

Thence, there is a developed interest in extracting and isolating industrially applicable fibre components from these valuable seaweeds. Seaweeds contain a diverse range of fibre components. Brown seaweeds contain alginate, laminarin and fucoidan polysaccharides; red seaweeds contain agar, carrageenan, porphyran and xylan; and green seaweeds contain ulvan, xylan and cellulose.

Obesity is a common chronic physical illness of modern society, and depression is the most prevalent psychological condition. Despite the high prevalence of these conditions concomitantly, sufficient exploration of any association between them may be associated with multiple metabolic disorders and/or simultaneous problems like lower HDL cholesterol, higher depressive symptoms, total caloric intake, higher waist circumference, blood pressure, total triglycerides and fasting glucose.

These challenges can be overcome by the advent of new nutraceutical formulation, which do ensure a bioenhancing, immune-stimulating and a drug adjunct effect in bioactivities. Using this natural candidate, the development of novel and effective therapeutic seaweeds' phycocolloids or compounds can be identified against various degenerative and deficiency diseases.

Due to the increasing interest of consumers for a potent, healthier and side effects free formulation, the pharmaceutical industry has to face the double challenge of producing healthier processed medicines. Consumer's psychology viz., easy access to medicines and assumed safety of herbal drugs, suitable is nutraceutical form only.

Edible seaweeds offer interesting possibilities to develop healthier drugs and are the formidable source of nutrients and bio-compounds with proven benefits against degenerative metabolic diseases. 
Fundamentals on seaweed potential as a promising share of nutraceuticals in alleviating the obese problem

\section{REFERENCES}

Abirami, R.G. (2012). Nutritional and Safety evaluation of Under exploited seaweeds and Nutraceutical Potentials of Ulva Fasciata. Avinashilingam University for Women India, Ph.D presentation.

Abirami, R.G., Kowsalya, S., Munisamy, S., Palaniappan, S., Sungkwon, P., Ahmed, H.A.F., Rajakrishnan, R.F., Rajagopal, F. and Balamuralikrishnan, B. (2020). A comparison of nutritional value of underexploited edible seaweeds with recommended dietary allowances. J. King. Saud. Univ. Sci., 32 : 1206-1211.

Abreu, M.H., Pereira, R., Yarish, C., Buschmann, A.H., SousaPinto, I. (2011b). IMTA with Gracilaria vermiculophylla: productivity and nutrient removal performance of the seaweed in a land-based pilot scale system. Aqua-culture, 312: 77-87.

Almela, C., Algora, S., Benito, V., Clemente, M.J., Devesa, V., Suner, M.A., Velez, D. and Montoro, R. (2002). Heavy metal, total arsenic, and inorganic arsenic contents of algae food products. J. Agric. Food Chem., 50 (4): 918-923.

Ayyad, S.E., Ezmirly, S.T. and Basaif, S.A. (2011). Anti-oxidant, cytotoxic, anti-tumour and preotective DNA damage metabolites from the red seaweed alga Sargassum sp. Pharmacognosy Res., 3 : 160-165.

Banu, A.T. and Mageswari, S.U. (2015). Nutritional status and effect of seaweed chocolate on anemic adolescent girls. Food Sci. Human Welln., 4 : 28-34.

Berteau, O. and Mulloy, B. (2003). Sulphated fucans, fresh perspectives; structures, functions and biological properties of sulphated fucans and an overview of enzymes active toward this class of polysaccharide. Glyco-biol.,13: 29R-40R.

Burtin, P. (2003). Nutritional value of seaweeds. Electron. J. Env. Agric. Food Chem., 2: 498-503.

Buschmann, A.H., Varela, D.A., Hernandez, G.M.C. and Huovinen, P. (1997) Opportunities and challenges for the devlopment of an integrated seaweed-based aquaculture activity in Chile; determining the physiological capabilities of Macrocystis and Gracilaria as biofilters. J. Appl. Phycol., 20: 571-577.

Cerna, M. (2011). Seaweed proteins and amino acids as nutraceuticals. Adv. Food Nutr. Res., 64 : 297-312.

Chakrabarti, S., Jahandideh, F. and Wu, J. (2014). Food-derived bioactive peptides on inflammation and oxidative stress. BioMed Res Int.

Chapman, V.J. and Chapman, D.J. (1980). Seaweeds and their uses. $3^{\text {rd }}$ Edition, Chapman and Hall, London, 62-67.
Cheenubhotla, V.S.K., Kaliaperumal, N. and Kalimuthu, S. (1987). Economically important seaweeds. CMFRI Bulletin, 41 : 3-19.

Chennubhotla, V.S.K., Kaliaperumal, N., Kalimuthu, S. and Ramalingam, J.R. (2004). Commercially important seaweeds of India, their occurrence, chemical products and uses. Mar. Fish. Infor. Serv. T\&E Ser., 107 : 11-16.

Chittimoju, S.B. and Pearce, E.N. (2019). Iodine deficiency and supplementation in pregnancy. Clin. Obstet. Gynecol., 62 : 330-338.

Chung, I.K., Kang, Y.H., Yarish, C., Kraemer, G.P. and Lee, J.A. (2002). Application of seaweed cultivation to the bioremediation of nutrient rich effluent. Algae, 17: 187194.

Cottier-cook, E.J., Nagabhatla, N., Badis, Y., Campbell, M. et al., Safeguarding the future of the global seaweed aquaculture industry. United Nation University (INWEH) and Scottish Association for Marine Science Policy Brief, South Hamilton, 12.

Dawczynski, C.H., Schubert, R. and Jahreis, G. (2007). Amino acids, fatty acids, and dietary fiber in edible seaweed products. Food Chem., 103: 891-899.

Dawcynski, C.H., Schafer, U., Leiterer, M. and Jahreis, G. (2007). Nutritional and toxicological importance of macro, trace, and ultra-trace elements in algae food products. J. Agric. Food Chem., 55: 10470-10475.

Fan, X., Bai, L., Zhu, L., Yang, L. and Zhang, X. (2014). Marine algae-derived bioactive peptides for human nutrition and health. J. Agric. Food Chem., 62 : 9211-9222.

Fleurence, J. (1999). Seaweed proteins, biochemical, nutritional aspects, and potential use. Trends Food Sci. Technol., 10: 25-28.

Hafting, J.T., Craigie, J.S., Stengel, D.B., Loureiro, R.R., Buschmann, A.H., Yarish, C., Edwards, M.D. and Critchley, A.T. (2015). Prospects and challenges for industrial production of seaweed bioactives. $I$. Phycol., 51: 821-837.

Han, J., Xing, D., Sun, H., Lu, H., Li, M. and Du, L. (2002) Comparison of flavonoids, terpenoids and their natural complex in Ginkgo biloba on anti-oxidant effect. Zhongguo. Yaolixue. Tongbao., 18 : 115-117.

Hayashi, L., Hurtado, A.Q., Msuya, F.E., Bleicher, L.G., and Critchley, A.T. (1999). A review of Kappaphycus farming: prospects and constraints.

Holloway, W.D., Tasman, J.C. and Lee, S.P. (1978). Digestion of certain fractions of dietary fiber in humans. Am. J. Clin. Nutr., 31: 927-930. 
Karpakavalli Meenakshisundaram, Muthumareeswari Sethurajan, Ranjithkumar Dhanaraj, Sangilimuthu Alagar Yadhav and Mohan Sellapppan

Hou, J. and Jin, Y., The healing power of Chinese herbs and medicinal recipes. Haworth Press, Inc., New York, 662.

Hou, X. and Yan, X. (1998). Study on the concentration and seasonal variation of inorganic elements in 35 species of marine algae. Sci. Total Environment, 222: 141156.

Hu, X., Li, Y. and Li, C. (2011). Combination of fucoxanthin and conjugated acid attenuates body weight gain and improves lipid metabolism in high-fat diet-induced obese rats. Arch. Biochem. Biophys, 519 : 59-65.

Israel, A., Einav, R. and Seckbach, J. (2000). Seaweeds and their role in Globally Changing Environments: Cellular origin, Life in Extreme Habitats and Astro biology. Springer, New York, 251-283.

Jimenez, E.A. and Sanches, M.F.J. (2000). Dietary fiber from edible seaweeds: chemical structure, physiochemical properties and effects on cholesterol metabolism. Nutr. Res., 4 : 585-598.

Kaliaperumal, N., Chennubhotla, V.S.K., Kalimuthu, S., Ramalingam, J.R., Selvaraj, M. and Najmuddin, M. (1987). Chemical composiion of seaweeds, CMFRI Bulletin, 41: 31-51.

Kaliaperumal, N. (1994). Seaweed resources of Tamil Nadu Coast. Biol. Edu., 11: 281-293.

Kaliaperumal, N. and Uthirasivan, P. (2001) Commercial scale production of agar from the red alga Gracilaria edulis (Gmelin) Silva. Seaweed Research \& Utilization, 23: 55-58.

Kilinc, B., Cirikm, S., Turan, G., Tekogul, H. and Koru, E. Seaweeds for Food and Industrial applications. Riieka, Croatia.

Kim, G.H., Moon, K.H., Kim, J.Y., Shim, J. and Klochkova, T.A. (2014a). A revaluation of algal disease in Korean Pyropia (Porphyra) sea farms and their economic impact. Algae, 29: 249-265.

Kim, S.K. and Pangestuti, R. (2011). Biological activities and potential health benefits of fucoxanthin derived fro marine brown algae. Adv. Food Nutr. Res., 64 : 111128.

Kolb, N., Vallorani, L., Milanovic, N. and Stocchi, V. (2004). Evaluation of marine algae Wakame (Undaria pinnatifida) and Kombu (Laminaria digitate japonica) as food supplements. Food Technol. Biotechnol., 42 : 57-61.

Kumar, C.S., Ganesan, P., Suresh, P.V. and Bhaskar, N. (2008) Seaweeds as a source of nutritionally beneficial compounds - A review. J. Food Sci. Technol., 45 : 1 -
8.

Li, B., Lu, F., Wei, X. and Zhao, R. (2008). Fucoidan: structure and bioactivity. Molecules, 13: 1671-1695.

Maeda, H., Tsukui, T., Sashima, T., Hosokawa, M. and Miyashita, K. (2008). Seaweed carotenoid, fucoxanthin, as multi-functional nutrient. Asia Pac. J. Clin. Nutr., 17: 196-199.

Marleau, S., Mellal, K., Huynh, D.N. and Ong, H. (2014). Potential peptides in atherosclerosis therapy. Granata $\mathrm{R}$, Isagaard $\mathrm{J}$. Cardiovascular issues in Endocrinology, Frontiers of Hormone Research, Karger, Basel, Switzerland, 43: 93-106.

McHugh, D.J. A guide to the seaweed industry, FAO Fisheries technical paper 441. Food and Agricultural organization of the United Nations, Rome.

Misurcova, L. (2008). New nutritional aspects and utilization of seaweed and freshwater algae in human diet. Thesis. TBU Zlin.

Miyashita, K. (2009). Function of marine carotenoids. Forum Nutr., 61: 136-146.

Norziah, M.H. and Ching, C.H.Y. (2000). Nutritional composition of edible seaweed Gracilaria changgi. Food Chem., 68 : 69-76.

Nutrient requirements and Recommended Dietary Allowances for Indians: A report of the expert group of the Indian Council of Medical Research (ICMR)

Riccioni, G. (2012). Marine carotenoids and oxidative stress. Marine Drugs, 10 : 116-118.

Schneeman, B.O. (1999). Fibre, inulin and oligofructose; similarities and differences. J. Nutr., 129 : 1242S$1427 \mathrm{~S}$.

Sohn, C.H. The seaweed resources of Korea. In Critchley AT and Ohno M. Seaweed resources of the World. Japan International Co-operation Agency, Yoko-suka, 1533.

Teas, J., Pino, S., Critchley, A. and Braverman, L.E. (2004). Variability of iodine content in common commercially available edible seaweeds. Thyroid., 14 : 836-841.

Thivy, F. (1960). Seaweed utilization in India. Proc Symp Algology, ICAR, New Delhi, 345-365.

Torres-Fuentes, C., Schellekens, H., Dinan, T.G. and Cryan, J.F. (2014). A natural solution for obesity; bioactives for the preparation and treatment of weight gain: A review, Nutr. Neurosci., 18: 49-65.

Walsh, C.T., Sandstead, H.H., Prasad, A.S., Newberne, P.M. and Fraker, P.J. (1994). Health effects and research priorities for the 1990s. Env. Health Persp., 102 : 5- 
Fundamentals on seaweed potential as a promising share of nutraceuticals in alleviating the obese problem

46.

WHO and FAO (2004). Vitamin and Mineral requirements in Human Nutrition. 2004 WHO, Geneva.

Yamamoto, Y., Fujisawa, A., Hara, A. and Dunlap, W.C. (2001). An unusual vitamin $\mathrm{E}$ constituent (á-tocomonoenol) provides enhanced antioxidant protection in marine organisms adapted to cold-water environments. Proc. Natl. Acad. Sci. USA, 98: 13144-13148.
Zaragoza, M.C., Lopez, D. and Saiz, P. (2008). Toxicity and anti-oxidant activity in vitro and in vivo of two Fucus vesiculosus extracts. J. Agric. Food Chem.,56, 77737780.

Zhang, Z., Zhang, P. and Hamada M.(2008). Potential chemoprevention effect of dietary fucoxanthin on urinary bladder cancer EJ-1 cell line. Oncol rep., 20 : 1099-1103.

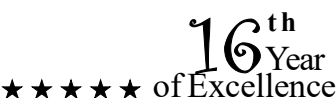

